\section{Lsh, a member of the SNF2 family, is required for genome-wide methylation}

\author{
Kathleen Dennis, Tao Fan, Theresa Geiman, \\ Qingsheng Yan, and Kathrin Muegge ${ }^{1}$
}

Laboratory of Molecular Immunoregulation, SAIC, National Cancer Institute at Frederick, Frederick, Maryland 21702-1201, USA

Methylation patterns of the mammalian genome are thought to be crucial for development. The precise mechanisms designating specific genomic loci for methylation are not known. Targeted deletion of $\mathbf{L s h}$ results in perinatal lethality with a rather normal development. We report here, however, that $\mathrm{Lsh}^{-/-}$mice show substantial loss of methylation throughout the genome. The hypomethylated loci comprise repetitive elements and single copy genes. This suggests that global genomic methylation is not absolutely required for normal embryogenesis. Based on the similarity of Lsh to other SNF2 chromatin remodeling proteins, it suggests that alteration of chromatin affects global methylation patterns in mice.

Received July 18, 2001; revised version accepted September 26, 2001.

Methylation of cytosine residues in the genome is thought to be crucial for normal development in mammals as well as plants, frogs, and fish. DNA methylation is involved in the regulation of a diverse range of biological processes such as genomic imprinting and X-chromosome inactivation (for reviews, see Yeivin and Razin 1993; Razin and Shemer 1995; Robertson and Jones 2000). Establishment of genomic methylation patterns in mammals is a highly orchestrated process, with almost complete erasure during early embryogenesis and a resetting of the pattern subsequent to implantation. In general, genes are relatively unmethylated in expressing tissues and methylated in nonexpressing tissues leading to the hypothesis that methylation controls tissue specific gene expression. Alternatively, genomic methylation may primarily protect against the expression of parasitic sequences (Walsh and Bestor 1999). Deletion of DNA methyltransferase in Xenopus leads to abnormal development of the embryo (Stancheva and Meehan 2000; Stancheva et al. 2001). Reports on mice that are deficient in DNA methyltransferases support also a role for methylation in development as these mice die early during embryogenesis (Li et al. 1992; Lei et al. 1996; Okano et al. 1999).

Lsh (lymphoid specific helicase) belongs to the family

[Key Words: Lsh; methylation; SNF2; SWI/SNF complex; chromatin] ${ }^{1}$ Corresponding author.

E-MAIL muegge@mail.ncifcrf.gov; FAX (301) 846-7077.

Article and publication are at http://www.genesdev.org/cgi/doi/10.1101/ gad.929101. of SNF2/helicases. SNF2-like proteins are frequently involved in chromatin remodeling (Jarvis et al. 1996). Lsh shows a preferential lymphoid expression pattern in adult mice and has been shown to be important for normal lymphoid development (Geiman et al. 1998; Geiman and Muegge 2000). However, a low expression of Lsh has been found in multiple embryonal tissues suggesting a broader role for $L s h$ in development (Geiman et al. 2001). SNF2-containing protein complexes can alter nucleosomal structure in vitro (Peterson and Workman 2000) and recombinant SNF2 homologs on their own can cause nucleosomal sliding along DNA (Hamiche et al. 1999; Langst et al. 1999). This in vitro activity of SNF2 family members is held responsible for altering chromatin accessibility in vivo. A recent study identified the gene Ddm1 (decrease in DNA methylation), another SNF2 family member, as a modulator of genomic methylation in Arabidopsis thaliana (Jeddeloh et al. 1999). The methylation system in plants appears to be highly conserved although homologs for the chromomethylases have not been identified in mammals, possibly because mammals primarily maintain CG methylation instead of methylation at CNG sites (Lindroth et al. 2001). This latter $D d m 1$ study suggests a relationship between regulation of chromatin structure and genomic methylation in plants. Because Ddm1 shares about 50\% identity with Lsh over the region containing the helicase domains (Jeddeloh et al. 1999|, we studied the effect of Lsh on genomic methylation patterns in mice.

\section{Results and Discussion}

To determine whether Lsh has an effect on DNA methylation we examined genomic DNA derived from $\mathrm{Lsh}^{-/}$ mice (Geiman and Muegge 2000; Geiman et al. 2001) for their methylation status at multiple repetitive sequences that are highly methylated. The minor satellite sequences $(50,000-100,000$ copies $)$ are located around centromeres. Analysis of genomic DNA from fibroblasts, brain, liver, intestine, heart and lung, and the whole body (Fig. 1A,B) as well as thymus (K. Dennis, T.M. Geiman, and K. Muegge, unpubl.) showed increased digestibility with HpaII, a methylation-sensitive enzyme. The pattern of the HpaII digest was comparable with the $M s p I$ digest (a methylation-insensitive isoschizomer) suggesting a substantial loss of methyl groups at the minor satellite sequence in the absence of Lsh. The defect in methylation was detectable in newborn tissue (Fig. 1B) as well as fetal tissue (Fig. 1A) as early as day 13.5 of gestation (the earliest time point we have examined).

To analyze whether hypomethylation is a widespread phenomenon in the genome, other methylated sequences with high copy number were examined. The major satellite sequence, with 700,000 copies in centromeric regions, also showed substantial hypomethylation in DNA isolated from fetal brain tissue of Lsh-deleted animals (Fig. 2) as well as from MEF cultures or body tissue of newborn mice (K. Dennis and K. Muegge, unpubl.). Sequences of the intracisternal A-particle retrovirus (IAP) (1000-2000 copies) are heavily methylated in littermate controls but not in Lsh-deleted animals. Line 1, another retroviral element $(50,000-100,000$ copies), Sine B1, the murine homolog of human Alu repeats, as well as examination of telomeric sequences showed sub- 
A

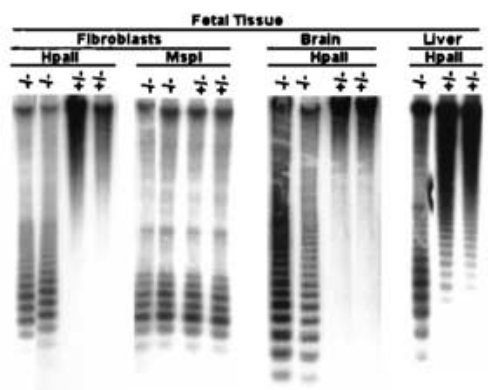

B

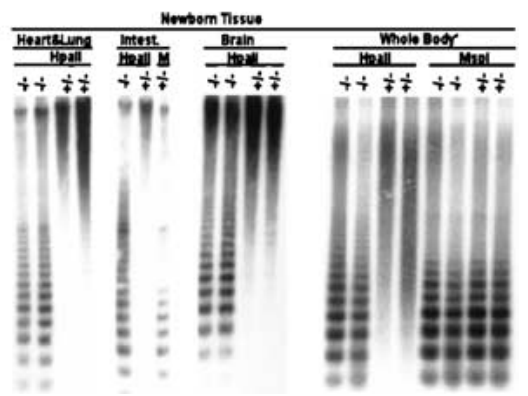

Figure 1. Hypomethylation of minor satellite sequences in $\mathrm{Lsh}^{-/}$ mice. (A) Southern analysis of genomic DNA derived at day 13.5 of gestation. DNA was digested with HpaII or MspI, blotted, and probed for minor satellite sequences using MR150. $(B)$ Southern analysis of genomic DNA derived from newborn mice within $24 \mathrm{~h}$ after birth. Whole body comprises every tissue with the exception of the examined internal organs. DNA was digested with HpaII or MspI, blotted, and probed for minor satellite sequences using MR150.

stantial hypomethylation in the absence of Lsh (Fig. 2). Moreover, comparison of $\mathrm{HpaII}$ and $\mathrm{MspI}$ digests of DNA from Lsh-deficient tissue appear almost indistinguishable suggesting substantial loss of methylation at the examined sites.

To determine whether Lsh deficiency selectively leads to hypomethylation of repetitive elements or also effects single copy sequences a number of specific genomic loci were examined. The genes for $\beta$-Globin and Pgk-2 (phosphoglycerate kinase) are highly methylated single copy genes with a tissue-specific expression pattern. Pgk-1, another highly methylated gene, is located on the $\mathrm{X}$-chromosome. The methylation sensitive sites examined were located either $5^{\prime}$ of the gene (Pgk-1), within the exon (Pgk-2), or $3^{\prime}$ of the gene (Globin) and did not con-
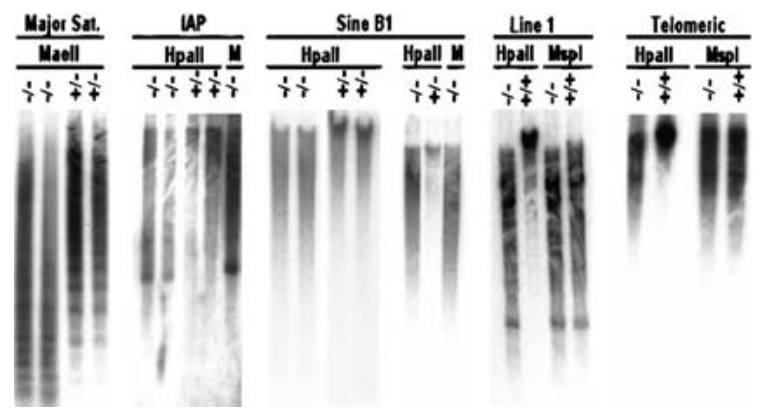

Figure 2. Hypomethylation of repetitive sequences in $\mathrm{Lsh}^{-/-}$mice. Southern analysis for repetitive sequences. Genomic DNA derived from $\mathrm{Lsh}^{-1-}$ or littermate controls was digested with MaeII and probed for major satellite sequences, or digested with HpaII and $\operatorname{MspI}(\mathrm{M})$ and probed for IAP, Sine B1, Line 1, or telomeric sequences. tain any known repetitive sequences (Singer-Sam et al. 1990; Kafri et al. 1992; Tada et al. 1997). All three examined loci revealed a substantial loss of methylation in newborn tissue as well as embryonic tissue from $\mathrm{Lsh}^{-1}$ mice (Fig. 3A-C). In addition, the upstream region of the H19 gene was examined comprising the imprinting control region with all four CTCF (CCCTC-binding factor) binding sites (Bell and Felsenfeld 1999). This region showed substantial hypomethylation in $\mathrm{Lsh}^{-/-}$mice (Fig. $3 \mathrm{D})$. In contrast the Igf2r gene showed no difference in methylation between $\mathrm{Lsh}^{-1-}$ tissue and wild-type tissue (K. Dennis and K. Muegge, unpubl.). These results demonstrate that loss of the Lsh gene effects methylation of repetitive elements and single-copy sequences including the imprinted region of the $H 19$ gene.

A global defect in methylation was visualized using ethidium bromide stain. Genomic DNA derived from thymus and MEF (Fig. 4A) as well as brain (K. Dennis and K. Muegge, unpubl.) of Lsh-deficient mice was highly digestible with the methylation-sensitive enzyme HpaII. To quantify the extent of hypomethylation, genomic DNA from $\mathrm{Lsh}^{-1-}$ mice was tested in vitro for its ability to accept methyl groups and compared with littermates using the SssI methyltransferase. Genomic DNA derived from embryonic liver and body as well as newborn brain of Lsh-deleted mice accepted two to three times more methylation than controls (Fig. 4B). Assuming an average methylation level of $60 \%-70 \%$ in control samples, this difference would suggest a genome-wide methylation level of only $13 \%-32 \%$ in genomic DNA from Lshdeleted mice. In addition, genomic DNA from newborn brain was digested with $M s p \mathrm{I}$, radiolabeled at $5^{\prime}$ ends, and degraded to single deoxynucleoside monophosphates. Cytosine as well as methyl-cytosine was sepa-
A

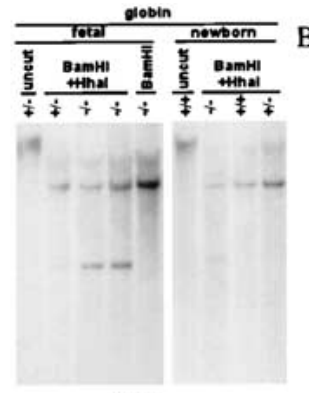

C

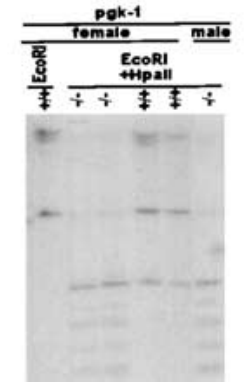

D

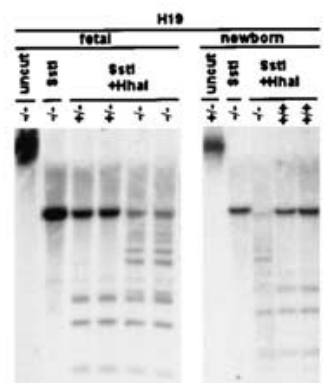

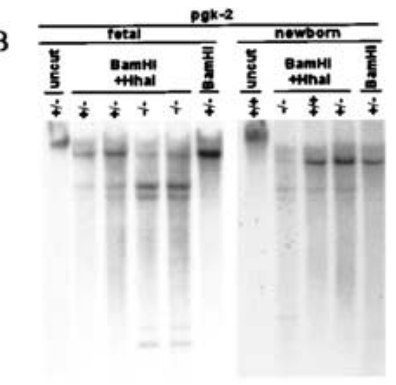

Figure 3. Hypomethylation of single copy sequences in $\mathrm{Lsh}^{-1}$ mice. (A) Southern analysis of the $\beta$-Globin gene. Genomic DNA was derived from newborn mice or embryos at day 13.5 gestation. DNA was digested with BamHI with or without the methylation sensitive restriction enzyme HhaI, blotted, and probed for $\beta$-Globin. $(B)$ Southern analysis of the Pgk-2 gene. (C) Southern analysis of the $P g k-1$ gene. (D) Southern analysis of the H19 upstream imprinted region. 
A

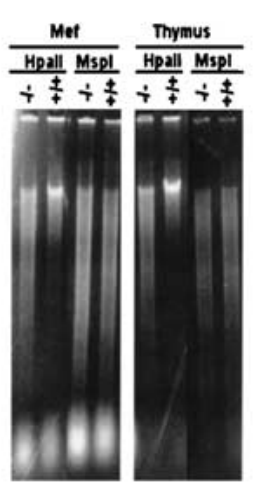

B

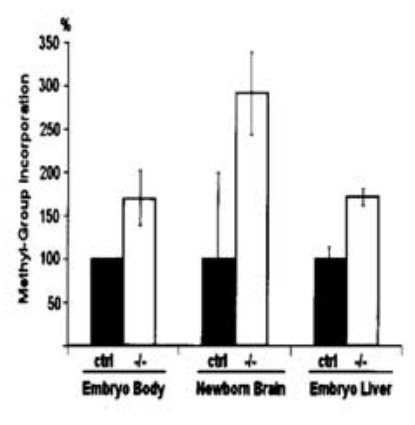

C

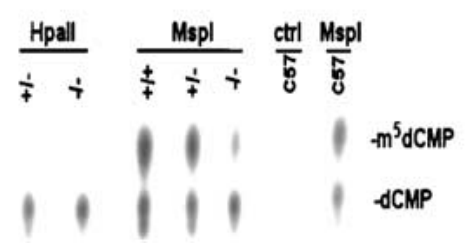

Figure 4. Global hypomethylation in $\mathrm{Lsh}^{-/-}$mice. (A) Genomic DNA from embryonal fibroblasts (MEF) or adult thymus from radiation chimeras (Geiman and Muegge 2000) was digested with the methylation-sensitive enzyme HpaII and the nonsensitive enzyme $M s p I$, subjected to agarose gel electrophoresis, and visualized by ethidium bromide stain. (B) Methyl acceptance assay. Equal amounts of genomic DNA derived from day 13.5 embryonic body, embryonic liver, or from newborn brain were methylated in vitro by SssI CG methylase using radiolabeled S-adenosyl-methionine as donor. This approach allows determination of the amount of unmethylated CG sites in the genome and serves as an indirect measurement of genomic methylation levels. The amount of incorporated radiolabeled methyl groups on cytosines per microgram of DNA was measured in Lsh deleted samples and control littermates as described previously (Antoun et al. 2000). (C) Direct measurement of methyl-cytosine in genomic DNA. Equal amounts of genomic DNA derived from brain samples of $\mathrm{Lsh}^{-/-}$mice and littermate controls were digested with MspI, radiolabeled at the $5^{\prime}$-ends, and digested with nuclease P1 to generate 5'-deoxymononucleotides. Cytosine and methyl-cytosine were separated by thin layer chromatography (Cedar et al. 1979) and quantified using PhosphorImager analysis. The ratio of methyl-cytosine to total cytosine indicates the level of methylation at all CCGG sites. HpaII digests should not generate methyl-cytosine spots and serve as controls, indicating the specificity of the assay.

rated by thin-layer chromatography and the resulting spots were quantified by PhosporImager. The control digest using HpaII did not show a spot for methylated cytosine indicating that the assay is highly specific. Whereas wild-type controls showed that about $57 \%$ of their genome was methylated, the Lsh-deleted mice show only $34 \%$ methylation at CCGG sites (Fig. 4C). Thus, loss of the Lsh gene resulted in a substantial loss of methylation throughout the genome.

We hypothesize that Lsh protein may participate in the process of de novo or maintenance DNA methylation rather than simply altering the level of DNA methyltransferase mRNA and protein for several reasons: (1) mRNA levels for DNA methyltransferases were comparable between Lsh-deficient samples and control samples in embryonic bodies (Fig. 5A), embryonic liver, or MEF cultures (T. Fan and K. Muegge, unpubl.). (2) The level of Dnmtl protein (whose targeted deletion results in a similar degree of genomic hypomethylation) is indistinguishable between $\mathrm{Lsh}^{-/-}$tissue and controls (Fig. 5B). Similarly, the amounts of Dnmt3a and Dnmt3b proteins were equally expressed in Lsh-deficient tissue and control sample (Fig. 5B). (3) Methyltransferase activity as measured from nuclear extracts from Lsh-deficient tissue was not significantly altered in comparison with control tissue (Fig. 5C). This also has been reported for mutants of the Ddm1 gene in A. thaliana (Jeddeloh et al. 1999) sharing a high similarity with Lsh. (4) The biological phenotype of $\mathrm{LSh}^{-/-}$mice is very distinct from that reported for either Dnmt1- or Dnmt3a/b-deficient embryos (Li et al. 1992; Okano et al. 1999; Geiman et al. 2001).

A global effect on methylation of the genome has thus far only been reported for embryos deficient in DNA methyltransferase. Dnmt $1 \mathrm{~N}$ is a targeted Dnmt1 allele that leads to a $95 \%$ reduction of the Dnmt1 protein. Mutant embryos develop to day 10.5 and show $30 \%$ reduction of genome methylation levels (Li et al. 1992). The S and C alleles of Dnmt1 are more severe and lead to an arrest in embryonic development around day 8.5 with an almost undetectable genomic methylation level. In contrast, conditional mutants that lack Dnmt1 from day 12 of gestation in neuroblasts die shortly after birth from respiratory stress without any obvious defects in the brain structure (Fan et al. 2001). The methyltransferases Dnmt3a and Dnmt3b are thought to be involved in de novo methylation. Dnmt $3 a^{-/-}$mice look normal at birth and die runted by 4 wk of age with no apparent change in global methylation levels (Okano et al. 1999). Dnmt3b could not be recovered at birth and showed developmen-
A

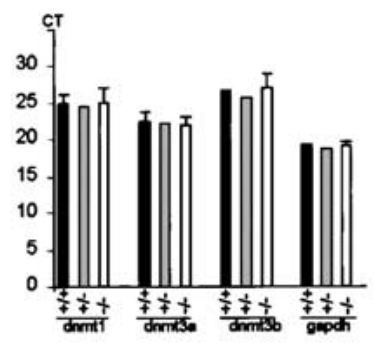

C

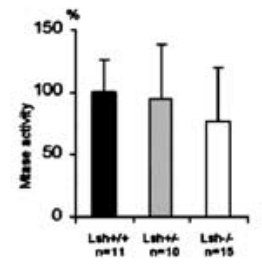

B

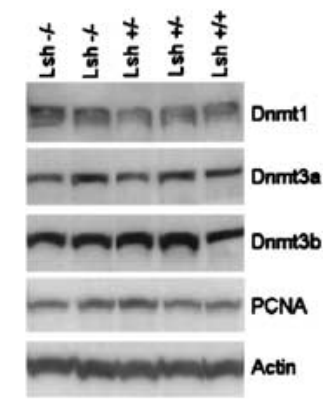

Figure 5. Expression of DNA methyltransferases and measurement of Mtase activity in $\mathrm{Lsh}^{-1-}$ mice. (A) RT-PCR analysis. Total RNA of embryonic body ( 2 wild type, 1 heterozygote, and 3 knockout) derived from day 17.5 gestation was reverse transcribed and subjected to real-time PCR analysis for measurement of Dnmt1, Dnmt3a, or $D n m t 3 b$ or Gapdh transcripts as control. (CT) Cycle threshold, cycle number at which each PCR reaction reaches a predetermined fluorescence threshold, set within the linear range of all reactions. (B) Western analysis. Cellular extracts derived from fetal brain tissue were analyzed using specific antiserum against murine Dnmt1, Dnmt3a (Imgenex), Dnmt3b (Affinity Bioreagents), $\beta$-Actin (Sigma), or PCNA (Santa Cruz) as control. A similar result was obtained using lysates derived from embryonic body of day 17.5 gestation. $(C)$ Mtase activity. Cellular extracts were prepared from indicated tissues and examined in vitro for their ability to transfer radio-labeled methyl-groups onto synthetic template poly[d(I-C)] poly[d(I-C)] $(\mathrm{Li}$ et al. 1992). Embryonic bodies are from day 13.5 gestation. 
tal abnormalities from day 9.5 on (Okano et al. 1999). Loss of Dnmt3b does not affect global methylation patterns but instead leads to hypomethylation of certain classes of sequences such as minor satellite sequences. Double mutants deficient in Dnmt3a and Dnmt3b show abnormalities from day 8.5 on and die before day 11.5 . Double deficient mutants show substantial losses of methylation in retroviral sequences, and major and minor satellite repeats (Okano et al. 1999), although less severely than reported here for $\mathrm{Lsh}^{-1-}$ mice (Figs. 1 and 2, cf. HpaII digests with MspI digests; Li et al. 1992; Okano et al. 1999). The defects in genomic methylation, as reported previously, lead to early arrest during embryogenesis. This is in contrast with the phenotype reported for Lsh-deficient mice (Geiman and Muegge 2000; Geiman et al. 2001): $\mathrm{Lsh}^{-/-}$mice can develop until term and die shortly after birth. $\mathrm{Lsh}^{-/-}$mice show reduced lymphoid numbers, renal lesions with signs of necrosis, and a $20 \%$ weight reduction at birth. However, otherwise they appear grossly normal by morphologic and histologic criteria despite their global methylation defect. Thus, normal methylation patterns of the genome are not absolutely required for murine development until birth. To date it remains unclear which loci in the genome require methylation for survival of the organism.

Based on its presumed chromatin remodeling activity we speculate that Lsh may regulate chromatin accessibilty for DNA methyltransferases. Because Lsh protein expression correlates with S-phase of the cell cycle (Geiman and Muegge 2000) Lsh may facilitate access of DNA methyltransferases to hemimethylated sites after replication occurs and thus co-operate to maintain methylation patterns. Alternatively, the presence of Lsh may protect against demethylase activities (Weiss et al. 1996; Ramchandani et al. 1999). Overall, $L s h^{-/-}$mice provide a valuable model in mammals for examining the relationship between chromatin remodeling and methylation.

Recent studies contributed much to our understanding of how DNA methylation can regulate chromatin accessibility (Nan et al. 1998; Ng et al. 1999; Wade et al. 1999). The deficiency in genomic methylation in $\mathrm{Lsh}^{-1-}$ mice suggests that the reverse is also true, that chromatin structure can have an impact on genomic methylation levels. In further support, it has recently been observed that ATRX, another protein with SNF2 similarity, can alter methylation patterns (Gibbons et al. 2000); however, in contrast to Lsh the effect is not global, but at distinct genomic sites (ribosomal 18s locus or an Y-specific satellite) and furthermore not only hypomethylation but also hypermethylation has been reported.

Aberrant methylation patterns have been suspected to promote tumorigenesis (Jones and Gonzalgo 1997; Baylin and Herman 2000) to be involved in the process of aging (Issa 2000) or to be causative for inherited diseases such as the ICF syndrome (Okano et al. 1999; Xu et al. 1999). The observed defect in global methylation in $\mathrm{LSh}^{-1-}$ mice will be a helpful tool to increase our understanding of the mechanism and consequences of specific genomic methylation patterns in disease.

\section{Materials and methods}

Southern analysis

Genomic DNA was prepared from the indicated tissues, digested, separated by electrophoresis on $1 \%$ agarose gels, and transferred by blotting on Nytran plus membranes (Schleicher\& Schuell). Membranes were hy- bridized overnight at $42^{\circ} \mathrm{C}$ in hybridization buffer (Amersham) with ${ }^{32} \mathrm{P}$ labeled probes and washed twice in $2 \times \mathrm{SSC} / 0.1 \% \mathrm{SDS}$ at $65^{\circ} \mathrm{C}$ or $42^{\circ} \mathrm{C}$ for $30 \mathrm{~min}$ and twice in $0.2 \times \mathrm{SSC} / 0.1 \% \mathrm{SDS}$ at $65^{\circ} \mathrm{C}$ or $42^{\circ} \mathrm{C}$ for $30 \mathrm{~min}$. The following oligonucleotide probes were used for detection of repetitive sequences: Major satellite (60-mer GenBank accession no. X06899, base pair 1-60), Linel (60-mer accession no. D84391, base pair 5670-5729), Sine B1 (27-mer accession no. AC002121, base pair 13464-13490), telomeric probe $\left[42-\right.$ mer, $5^{\prime}-\left(\right.$ TTAGGG) $\left.\times 7-3^{\prime}\right]$. The minor satellite probe was a 66-mer oligonucleotide 5'-GACTGAAAAACACATTCGTTG GAAACGGGATTTGTAGAACAGTGTATATCAATGAGTTACAATG AG-3' as described elsewhere (Tada et al. 1997). The IAP probe was 299 bp long and derived by PCR reaction as described below. The detection of the methylation sensitive sites and maps for the $\beta$-globin, Pgk-2, and $P g k-1$ genes have been described elsewhere (Singer-Sam et al. 1990; Kafri et al. 1992; Tada et al. 1997). Examination of the 5' region of the H19 gene (including a map of the region) has been described (Tada et al. 1997). The 3.8-kb SacI fragment used as a probe was amplified by PCR reaction as described below. The probe comprises the imprinting control region with all four CTCF-binding sites and examines eight distinct $H$ haI sites.

$R T-P C R$ analysis

For detection of mRNA for DNA methyltransferases $2 \mu \mathrm{g}$ of total RNA was reversed transcribed. Real-time PCR was perfomed in the ABI PRISM 7900 Sequence Detection System (Applied Biosystems) using SYBR Green I as a double-strand DNA-specific binding dye and continuous fluorescence monitoring. Each reaction contained $100 \mathrm{ng}$ of cDNA template and primers at a concentration of $400 \mathrm{nM}$ in a final volume of $25 \mu \mathrm{L}$ in SYBR Green PCR Master Mix (Applied Biosystems) containing AmpliTaq Gold. PCR was initiated with one cycle $50^{\circ} \mathrm{C}$ for 2 min and one cycle $94^{\circ} \mathrm{C}$ for $10 \mathrm{~min}$ followed by 40 cycles: $94^{\circ} \mathrm{C}$ for $30 \mathrm{sec}, 60^{\circ} \mathrm{C}$ for 30 $\mathrm{sec}, 72^{\circ} \mathrm{C}$ for $45 \mathrm{sec}$. Cycle threshold, the cycle number at which each PCR reaction reaches a predetermined fluorescence threshold, was set within the linear range of all reactions. Melting curve analysis of amplification products was performed at the end of each PCR. As an additional control, PCR products were separated by electrophoresis and detected by hybridization with an internal oligonucleotide probe. The following oligonucleotides were used as primers: dnmtl (GenBank accession no. X14805: sense base pair 310-330, antisense base pair 681-701), dnmt3a (accession no. AF068625: sense base pair 363-382, antisense base pair 759-779), dnmt3b (accession no. AF068628: sense base pair 305-328, antisense base pair 818-838).

Quantitative measurement of global methylation

Measurement of methylated cytosine at CCGG sites was determined as described previously (Cedar et al. 1979; Li et al. 1992). Purified genomic DNA was digested with HpaII or MspI, treated with alkaline phosphatase and radiolabeled with $\left[\alpha-{ }^{32} \mathrm{P}\right]$ at the $5^{\prime}$-termini using polynucleotide kinase. Phenol-chloroform-purified DNA was digested with nuclease P1 and the $5^{\prime}$-deoxymononucleotides were separated by thin-layer chromatography on cellulose plates. The radioactivity over methyl-cytosine and cytosine was scanned by PhosphorImager analysis. The ratio was formed between methyl-cytosine versus total cytosine indicating the percentage of methylation at CCGG sites in the genome. HpaII was used as control digest indicating the specificity of the assay; as HpaII does not recognize methylated CCGG sites and only cleaves unmethylated sites the HpaII digest should only generate cytosine and not methyl-cytosine spots. The methyl acceptor assay was performed as described previously (Antoun et al. 2000). Purified genomic DNA (200 ng) was incubated for $4 \mathrm{~h}$ at $37^{\circ} \mathrm{C}$ with 4 units of M.SssI CpG methylase, $3 \mu \mathrm{Ci}$ [methyl ${ }^{3} \mathrm{H}$ ]S-adenosyl $\mathrm{L}$-methionine, and $1.5 \mu \mathrm{M}$ nonradioactive AdoMet. After termination the mixture was spotted on Whatman glass filters washed with $5 \%$ trichloroacetic acid, followed by $70 \%$ ethanol and the incorporated radioactivity was quantified by liquid scintillation counting.

Mtase activity

Measurement of DNA methyltransferase activity was performed as described previously (Li et al. 1992). Protein extract ( $20 \mu \mathrm{g}$ ) was added to 5 $\mu \mathrm{Ci}$ of $\left[\right.$ methyl $\left.{ }^{3} \mathrm{H}\right] \mathrm{S}$-adenosyl L-methionine and $4 \mu \mathrm{g}$ of poly[d(I-C)]poly[d(I-C)]. After incubation for $2 \mathrm{~h}$ at $37^{\circ} \mathrm{C}$, followed by phenol-chloroform extraction the nucleic acids in the aqueous phase were denatured, neutralized, and precipitated and the radioactivity that was incorporated into DNA was quantified by scintillation counting. 


\section{Acknowledgments}

We thank Drs. Scott Durum, Howard Young, Joost Oppenheim, and Timothy Bestor for their suggestions on the manuscript and helpful discussions. We thank Dr. Narayan Bhat and James Cherry for their help on using real-time PCR analysis. We thank Dr. Timothy Bestor for the generous gift of the murine Dnmtl antiserum. We thank Dr. Chun Wun for his generous gift of the murine Dnmt3a antiserum. We are grateful to the technical assistance of Rodney Wiles and Terry Stull. This project has been funded in whole or part with Federal funds from the National Cancer Institute, National Institutes of Health, under contract No. N01-C056000 .

The publication costs of this article were defrayed in part by payment of page charges. This article must therefore be hereby marked "advertisement" in accordance with 18 USC section 1734 solely to indicate this fact.

\section{References}

Antoun, G., Baylin, S.B., and Ali-Osman, F. 2000. DNA methyltransferase levels and altered CpG methylation in the total genome and in the GSTP1 gene in human glioma cells transfected with sense and antisense DNA methyltransferase cDNA. I. Cell. Biochem. 77: 372 381.

Baylin, S.B. and Herman, J.G. 2000. DNA hypermethylation in tumorigenesis: Epigenetics joins genetics. Trends Genet. 16: 168-174.

Bell, A.C. and Felsenfeld, G. 2000. Methylation of a CTCF-dependent boundary controls imprinted expression of the Igf2 gene. Nature 405: 482-485.

Cedar, H., Solage, A., Glaser, G., and Razin, A. 1979. Direct detection of methylated cytosine in DNA by use of the restriction enzyme MspI. Nucleic Acids Res. 6: 2125-2132.

Fan, G., Beard, C., Chen, R.Z., Csankovszki, G., Sun, Y., Siniaia, M., Biniszkiewicz, D., Bates, B., Lee, P.P., Kuhn, R., et al. 2001. DNA hypomethylation perturbs the function and survival of CNS neurons in postnatal animals. I. Neurosci. 21: 788-797.

Geiman, T.M. and Muegge, K. 2000. Lsh, an SNF2/helicase family member, is required for proliferation of mature T lymphocytes. Proc. Natl. Acad. Sci. 97: 4772-4777.

Geiman, T.M., Durum, S.K., and Muegge, K. 1998. Characterization of gene expression, genomic structure, and chromosomallocalization of Hells (Lsh). Genomics 54: 477-483.

Geiman, T.M., Tessarollo, L., Anver, M.R., Kopp, J.B., Ward, J.M., and Muegge, K. 2001. Lsh, a SNF2 family member, is required for normal murine development. Biochim. Biophys. Acta 1526: 211-220.

Gibbons, R.J., McDowell, T.L., Raman, S., O'Rourke, D.M., Garrick, D., Ayyub, H., and Higgs, D.R. 2000. Mutations in ATRX, encoding a SWI/SNF-like protein, cause diverse changes in thepattern of DNA methylation. Nat. Genet. 24: 368-371.

Hamiche, A., Sandaltzopoulos, R., Gdula, D.A, and Wu, C. 1999. ATPdependent histone octamer sliding mediated by the chromatin re modeling complex NURF. Cell 97: 833-842.

Issa, J.P. 2000. CpG-island methylation in aging and cancer. Curr. Top. Microbiol. Immunol. 249: 101-118.

Jarvis, C.D., Geiman, T., Vila-Storm, M.P., Osipovich, O., Akella, U., Candeias, S., Nathan, I., Durum, S.K., and Muegge, K. 1996. A novel putative helicase produced in early murine lymphocytes. Gene 169: 203-207.

Jeddeloh, J.A., Stokes, T.L., and Richards, E.J. 1999. Maintenance of genomic methylation requires a SWI2/SNF2-like protein. Nat. Genet 22: 94-97.

Jones, P.A. and Gonzalgo, M.L. 1997. Altered DNA methylation and genome instability: A new pathway to cancer? Proc. Natl. Acad. Sci. 94: 2103-2105.

Kafri, T., Ariel, M., Brandeis, M., Shemer, R., Urven, L., McCarrey, J., Cedar, H., and Razin, A. 1992. Developmental pattern of gene-specific DNA methylation in the mouse embryo and germ line. Genes \& Dev. 6: 705-714.

Langst, G., Bonte, E.J., Corona, D.F., and Becker, P.B. 1999. Nucleosome movement by CHRAC and ISWI without disruption or trans-displacementof the histone octamer. Cell 97: 843-852.

Lei, H., Oh, S.P., Okano, M., Juttermann, R., Goss, K.A., Jaenisch, R., and Li, E. 1996. De novo DNA cytosine methyltransferase activities in mouse embryonic stem cells. Development 122: 3195-3205.
Li, E., Bestor, T.H., and Jaenisch, R. 1992. Targeted mutation of the DNA methyltransferase gene results in embryonic lethality. Cell 69: 915926.

Lindroth, A.M., Cao, X., Jackson, J.P., Zilberman, D., McCallum, C.M. Henikoff, S., and Jacobsen, S.E. 2001. Requirement of CHROMOMETHYLASE3 for maintenance of CpXpG methylation. Science 292: 2077-2080.

Nan, X., Ng, H.H., Johnson, C.A., Laherty, C.D., Turner, B.M., Eisenman R.N., and Bird, A. 1998. Transcriptional repression by the methyl CpG-binding protein MeCP2 involves a histone deacetylase complex. Nature 393: 386-389.

Ng, H.H., Zhang, Y., Hendrich, B., Johnson, C.A., Turner, B.M., Erdjument-Bromage, H., Tempst, P., Reinberg, D., and Bird, A. 1999. MBD2 is a transcriptional repressor belonging to the MeCP1 histone deacetylasecomplex. Nat. Genet. 23: 58-61.

Okano, M., Bell, D.W., Haber, D.A., and Li, E. 1999. DNA methyltransferases Dnmt3a and Dnmt3b are essential for de novo methylation and mammalian development. Cell 99: 247-257.

Peterson, C.L. and Workman, J.L. 2000. Promoter targeting and chromatin remodeling by the SWI/SNF complex. Curr. Opin. Genet. Dev. 10: $187-192$

Ramchandani, S., Bhattacharya, S.K., Cervoni, N., and Szyf, M. 1999. DNA methylation is a reversible biological signal. Proc. Natl. Acad. Sci. 96: 6107-6112.

Razin, A. and Shemer, R. 1995. DNA methylation in early development. Hum. Mol. Genet. 4: 1751-1755.

Robertson, K.D. and Jones, P.A. 2000. DNA methylation: past, present and future directions. Carcinogenesis 21: 461-467.

Singer-Sam, J., Grant, M., LeBon, J.M., Okuyama, K., Chapman, V. Monk, M., and Riggs, A.D. 1990. Use of a HpaII-polymerase chain reaction assay to study DNA methylation in the Pgk-1 CpG island of mouse embryos at the time of X-chromosome inactivation. Mol. Cell. Biol. 10: 4987-4989.

Stancheva, I. and Meehan, R.R. 2000. Transient depletion of xDnmtl leads to premature gene activation in Xenopus embryos. Genes \& Dev. 14: 313-327.

Stancheva, I., Hensey, C., and Meehan, R.R. 2001. Loss of the maintenance methyltransferase, $\mathrm{xDnmt1}$, induces apoptosis in Xenopus embryos. EMBO J. 20: 1963-1973.

Tada, M., Tada, T., Lefebvre, L., Barton, S.C., and Surani, M.A. 1997. Embryonic germ cells induce epigenetic reprogramming of somatic nucleus inhybrid cells. EMBO J. 16: 6510-6520.

Wade, P.A., Gegonne, A., Jones, P.L., Ballestar, E., Aubry, F., and Wolffe, A.P. 1999. Mi-2 complex couples DNA methylation to chromatin remodelling and histonedeacetylation. Nat. Genet. 23: 62-66.

Walsh, C.P. and Bestor, T.H. 1999. Cytosine methylation and mammalian development. Genes \& Dev. 13: 26-34.

Weiss, A., Keshet, I., Razin, A., and Cedar, H. 1996. DNA demethylation in vitro: Involvement of RNA. Cell 86: 709-718.

Xu, G.L., Bestor, T.H., Bourc'his, D., Hsieh, C.L., Tommerup, N., Bugge, M., Hulten, M., Qu, X., Russo, J.J., and Viegas-Pequignot, E. 1999 Chromosome instability and immunodeficiency syndrome caused by mutations in a DNA methyltransferase gene. Nature 402: 187-191.

Yeivin, A. and Razin, A. 1993. Gene methylation patterns and expression. EXS 64: 523-568. 


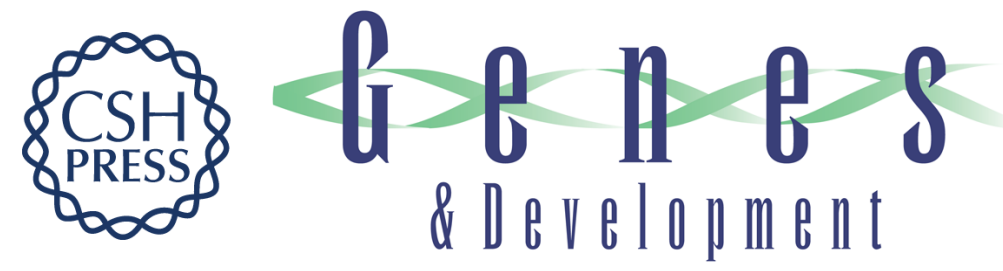

\section{Lsh, a member of the SNF2 family, is required for genome-wide methylation}

Kathleen Dennis, Tao Fan, Theresa Geiman, et al.

Genes Dev. 2001, 15:

Access the most recent version at doi:10.1101/gad.929101

References This article cites 35 articles, 11 of which can be accessed free at: http://genesdev.cshlp.org/content/15/22/2940.full.html\#ref-list-1

License

Email Alerting

Receive free email alerts when new articles cite this article - sign up in the box at the top Service right corner of the article or click here.

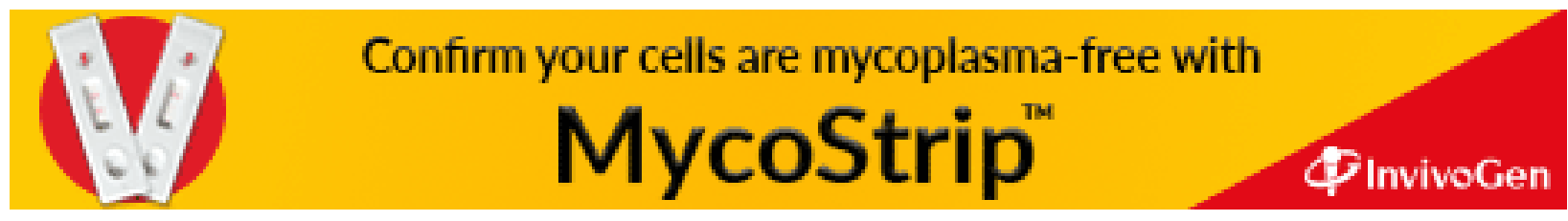

